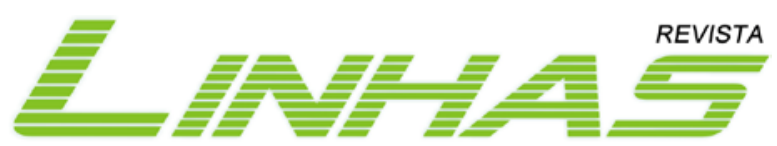

\title{
TECNOLOGIA, EDUCAÇÃO A DISTÂNCIA E APRENDIZAGEM DE LÍNGUAS
}

\author{
Luís Salema*
}

\section{Resumo}

O desenvolvimento tecnológico tem possibilitado o aparecimento de novos media digitais que alteraram profundamente as formas de aprender e de ensinar. A integração desses media, no ensino, constitui um desafio para os professores, enquanto agentes do desenvolvimento curricular. Partindo de um conjunto de questões referente à utilização da tecnologia, na aprendizagem de línguas, este artigo apresenta uma revisão de alguns trabalhos realizados nesse âmbito. A abordagem assenta em enquadramentos concetuais ligados à tecnologia educativa, à didática das línguas e à educação a distância. A aprendizagem de línguas, fundamentada numa perspetiva construtivista, e em ambientes tecnologicamente ricos e significativos, constitui uma forma holística de desenvolver a competência comunicativa dos estudantes. A sociedade em rede tem facilitado o aparecimento de outras maneiras de aprender línguas, com a interação oral a ganhar uma importância crescente, em contextos de e-learning.

Palavras-chave: Desenvolvimento curricular. Tecnologia educativa. Aprendizagem de línguas. Educação a distância.

\section{TECNOLOGY, DISTANCE EDUCATION AND LANGUAGES LEARNING}

\begin{abstract}
Technological development has fostered the emergence of new digital media that have profoundly changed current learning and teaching methods. The integration of these media in the classroom is a challenge for teachers as agents of curriculum development. Considering a set of questions regarding the use of technology in language learning methodology, this paper aims to review the scope of these issues, clarifying the results of the work already developed in this area. The approach is based on frameworks related to educational technology, language teaching methods and distance education. Language learning grounded on a constructive perspective and on technologically rich and significant environments is a holistic way of developing student's communicative competence. Online social networks have greatly contributed to the emergence of different ways of learning and teaching languages, with important emphasis on oral skills in e-learning contexts.
\end{abstract}

Keywords: Curriculum development. Educational technology. Language learning. Distance education.

\footnotetext{
* Doutorando em Educação (educação a distância e e-learning) e Tutor no Departamento de Educação e Ensino a Distância - Universidade Aberta (Portugal). Professor na Escola Secundária Manuel Teixeira Gomes - Portimão. E-mail: pintosalema@gmail.com
} 


\section{Introdução}

Marshall McLuhan, no ensaio Compreender os meios de comunicação - extensões do homem, escrevia, em 1964, que qualquer tecnologia é um prolongamento do ser humano. O livro, o telefone e o computador são extensões da nossa memória, da nossa voz e do nosso cérebro, respetivamente (McLUHAN, 2008 [1964]). Como extensões de nós próprios, os novos media amplificam e modificam as nossas funções cognitivas, condicionando a forma como vemos o mundo, como pensamos e como aprendemos.

O impacto da tecnologia na sociedade contemporânea implicou uma mudança na forma de entender o processo de ensino-aprendizagem, colocando novos desafios à escola, aos professores e aos alunos. Num mundo globalizado e cada vez mais ligado em rede, a comunicação entre os indivíduos tornou-se mais interativa, mais rápida e transnacional. Neste contexto, o domínio da língua materna assume-se como um saber fundamental para que o acesso à informação seja uma realidade. Para além desse domínio, tornou-se imprescindível o conhecimento de línguas estrangeiras, condição fundamental para a mobilidade dos indivíduos, seja por motivos profissionais, seja por razões académicas ou de lazer.

Línguas e tecnologias constituem um par indissociável e, do ponto de vista do desenvolvimento curricular, colocam um conjunto de questões aos professores e aos decisores das políticas educativas, a que se procura responder neste artigo:

i) Como enquadrar a tecnologia no ensino das línguas?

ii) Quais as tecnologias mais adequadas para uma determinada experiência de aprendizagem, nas aulas de língua?

iii) Que desafios coloca a aprendizagem de línguas, na modalidade de e-learning?

iv) Que desafios reserva o futuro, nesta área curricular, no que diz respeito à utilização da tecnologia?

Este artigo inicia-se com um enquadramento teórico que pretende realçar as implicações metodológicas que estão subjacentes à utilização dos novos media, salientando a importância e o papel do professor, na criação e na implementação de um ambiente tecnologicamente atrativo e significativo, do ponto de vista das aprendizagens.

Partindo deste enquadramento teórico geral, na segunda parte, são apresentados exemplos de atividades específicas para as aulas de língua, tendo em conta as diferentes 
dimensões do saber linguístico e as potencialidades dos novos media.

A terceira parte deste trabalho centra-se na aprendizagem de línguas, em ambientes de e-learning, cada vez mais procurados por indivíduos que pretendem adquirir novos saberes, ao longo da vida.

Por último, lança-se um breve olhar sobre os desafios que se colocam, futuramente, no âmbito do ensino e da aprendizagem das línguas, recorrendo às novas tecnologias.

\section{Tecnologia e curriculum}

Numa arguta e documentada reflexão, Harris et al. (2009) apresentam cinco tipologias de abordagem à integração da tecnologia, nas salas de aula, ora mais centradas no software utilizado, ora na exploração de recursos online, passando por reformas educativas centradas no esforço de utilização das novas tecnologias. Neste contexto, não tem sido esquecida a formação dos docentes que, conforme arguem os autores, nem sempre responde às necessidades específicas de uma dada disciplina. À luz do pensamento destes autores, se a tecnologia não for utilizada de acordo com o conteúdo que é trabalhado e com o público a quem se destina, o seu contributo para a aprendizagem será mínimo.

A utilização da tecnologia deve, pois, centrar-se numa área de interseção entre o conhecimento tecnológico, o conhecimento pedagógico e o conhecimento do conteúdo. Mishra \& Koehler (2006) traçaram um quadro concetual que sintetiza o conhecimento requerido ao professor, para uma efetiva integração da tecnologia, de modo a proporcionar aprendizagens significativas. Essa moldura teórica, designada Technological Pedagogical Content Knowledge-TPACK resulta num conhecimento múltiplo, agregador e integrador dos vários saberes hoje exigidos ao professor.

Nesta moldura teórica, o conhecimento do conteúdo refere-se às matérias que têm de ser ensinadas e aos hábitos específicos de cada disciplina (HARRIS et al., 2009; CANOLE e ALEVIZOU, 2010). Inclui, por isso, noções, teorias e ideias, ou seja, um conjunto de saberes que uma determinada área científica legitima. O conhecimento pedagógico materializa-se no domínio das práticas, dos objetivos e das estratégias que são mobilizados para a gestão da sala de aula, para além da capacidade de planificar. São, pois, saberes que se situam ao nível da execução e da periexecução do processo de ensino e de aprendizagem (ANDRADE, ARAÚJO \& SÁ, 1992), consubstanciando uma articulação entre a teoria e a prática. O conhecimento tecnológico refere-se à interação que o professor consegue estabelecer com as 
várias tecnologias disponíveis. Trata-se de um tipo de conhecimento que está em constante evolução, pois, como salientam Harris et al. (2009, p. 398): «[...] any definition of technology knowledge is in danger of becoming outdate $[\ldots]^{1} »$. No que diz respeito ao conhecimento pedagógico do conteúdo, este resulta da interação do conhecimento do conteúdo e do conhecimento pedagógico. Manifesta-se, por exemplo, na capacidade que o professor tem para identificar as competências e os saberes prévios dos alunos e para os articular com o processo de construção das novas aprendizagens. É este saber que permite ao professor (des)construir o conhecimento do conteúdo, em unidades mais simples, em função de cada turma, de cada ano e de cada escola.

Se o conjunto de conhecimentos atrás referido foi, durante muitos anos, suficiente para o desenvolvimento do processo de ensino-aprendizagem, constituindo o núcleo central das competências e saberes de qualquer professor, com a introdução de novas tecnologias, na sala de aula, tornou-se imperativo o conhecimento tecnológico pedagógico, ou seja, o entendimento que o professor tem relativamente ao impacto de uma determinada tecnologia, nos atos de ensinar e de aprender. Cabe ao professor avaliar as vantagens e os constrangimentos associados a um dado medium, selecionando, assim, aquele que melhor poderá servir o seu contexto de ensino e de aprendizagem. De facto, muitas tecnologias não são desenhadas especificamente para um contexto educativo e o professor, enquanto agente do desenvolvimento curricular, terá de adaptar essas tecnologias aos fins pedagógicos que tem em mente. Por isso, o professor mobiliza, também, o seu conhecimento tecnológico do conteúdo, ou seja, a capacidade de avaliar a relação que se estabelece entre um dado item programático e a tecnologia que é utilizada, aquando da sua abordagem.

Do diálogo existente entre estes diferentes tipos de conhecimento surge, então, o TPACK, um «pacote» de conhecimentos que, de forma sincrética, constitui um repositório dos saberes e das competências ligados ao conteúdo, à pedagogia e à tecnologia. Dessa junção emana um halo, resultante da interação que se estabelece entre esses diferentes domínios e o contexto em que a ação pedagógica se insere, permitindo decisões mais fundamentadas e adequadas. As especificidades decorrentes do conteúdo e da atividade a realizar implicarão (ou não) a utilização de uma determinada tecnologia, potenciadora dos «habits of mind» específicos de cada disciplina (HARRIS et al., 2009) e, consequentemente, de uma aprendizagem significativa. Trata-se, pois, de um conhecimento em ação, de um conhecimento pragmático (HARRIS \& HOFER, 2009), fruto de uma análise reflexiva da

\footnotetext{
${ }^{1}$ «[...] qualquer definição de conhecimento da tecnologia corre o risco de se tornar desatualizada [...]»
} 
praxis.

No contexto da sociedade da informação, o diálogo entre os contributos da tecnologia educativa e os da teoria curricular revela-se determinante para a construção de uma profissionalidade docente informada e capaz de responder aos novos desafios da educação. Esses desafios, impostos pelas novas tecnologias, pelas constantes necessidades de aprendizagem e pelas rápidas mudanças da sociedade moderna, altamente mediatizada, colocam uma questão permanente: como integrar os avanços registados nas ciências da educação e a investigação na área da tecnologia educativa, no desenho e no desenvolvimento curricular? Para que a resposta a esta questão seja possível, o currículo terá de ser entendido como um work in progress, em que a dimensão tecnológica é uma das suas componentes e, simultaneamente, um elemento para a sua construção: a tecnologia não é posta ao serviço do desenvolvimento curricular, como se de algo externo se tratasse, mas é parte integrante desse processo.

O desenvolvimento tecnológico potenciou a generalização e o aperfeiçoamento das redes de comunicação (MILTON, 2002), permitindo um maior número de situações de interação verbal com indivíduos de diferentes países, falantes de outras línguas. Para além disso, um bom desempenho na língua materna é essencial para o domínio de outros idiomas, contribuindo, simultaneamente, para a preservação da identidade de um povo e das línguas minoritárias (COMISSÂO DAS COMUNIDADES EUROPEIAS, 2008; CONDE, 2012; UNESCO, 2004). Num mundo e numa Europa que se querem multiculturais e plurilingues (ARAÚJO, 2011; COMISSÃO DAS COMUNIDADES EUROPEIAS, 2003; 2008), as tecnologias podem dar um importante contributo para a educação em línguas.

\section{Tecnologia e ensino-aprendizagem de línguas}

Apesar da multiplicidade de recursos e do surgimento de modelos teóricos, como o que se apresentou anteriormente, a utilização da tecnologia, por parte dos professores de línguas, continua a merecer algumas reticências. Por um lado, os docentes sentem-se mais confortáveis em ambientes em que o texto goza de maior centralidade; por outro, e não dissociado do anterior, muitos docentes apresentam, ainda, uma competência de literacia tecnológica pouco desenvolvida (POP, 2010), ou, conforme o preconizado no quadro teórico apresentado inicialmente, um conhecimento pedagógico tecnológico do conteúdo ainda pouco sistematizado. 
Ao longo dos séculos, a aprendizagem de línguas tem servido vários objetivos (BERTRAND, 1977; RUBIN \& THOMPSON, 1994), que não o meramente utilitário. Até ao século XIX, a aprendizagem de uma língua centrava-se no domínio das regras da sua gramática, nomeadamente na sintaxe e na tradução (ARAÚJO, 2011; MILTON, 2002).

A partir do início do século XX, o foco na aprendizagem das línguas foi-se deslocando, progressivamente, para o desenvolvimento das competências de oralidade. A constante utilização da língua materna, característica do método de tradução gramatical, cedeu o lugar à resolução de exercícios repetitivos, sempre na língua estrangeira, e à audição de cassetes, visando a correção da pronúncia e a ausência de erros gramaticais (ARAÚJO, 2011). Sobretudo até aos anos 70, a vulgarização dos suportes de gravação em áudio contribuiu para o aparecimento dos laboratórios de línguas, que permitiam gravar as produções orais dos estudantes e estabelecer o confronto com as de falantes nativos. Contudo, nem sempre os resultados alcançados foram os melhores (MILTON, 2002), pois os alunos revelavam-se «[...] incapazes de produzir enunciados longos, de adequar o registo à situação de enunciação, de ler textos complexos como o literário ou outros documentos culturais» (ANDRADE, ARAÚJO \& SÁ, 1992, p. 39).

Com o aparecimento dos novos media digitais e da sociedade em rede, os professores de línguas e os alunos passaram a ter à sua disposição múltiplas formas de aceder ao saber linguístico e cultural. Os wikis, os blogues, os podcast, o YouTube e o iTunes são, apenas, alguns dos muitos recursos que hoje podem ser utilizados nas aulas de línguas (ALIMEMAJ, 2010; CONOLE \& ALEVIZOU, 2010; COUTINHO \& BOTTENTUIT JUNIOR, 2008; FITZPATRICK, 2004; FRANKLIN \& HARMELEN, 2007; HAMPEL \& HAUCK, 2006; LENHART et al. , 2008; PAIVA, s.d.; WHEELER, 2009).

A utilização dos wikis e dos blogues apresenta um enorme potencial educativo, na educação em línguas, permitindo a implementação de processos de escrita colaborativa (COUTINHO \& BOTTENTUIT JUNIOR, 2008). Os podcast revelam-se uma ferramenta bastante útil para a aprendizagem de línguas, permitindo a gravação de diálogos que o estudante poderá ouvir posteriormente e, até, partilhar com os colegas online, criando-se, assim, um ambiente de aprendizagem menos convencional (COUTINHO \& BOTTENTUIT JUNIOR, 2008). No que diz respeito ao YouTube, nele encontram-se produções de falantes nativos, em situações formais e informais, que podem ser analisadas, quer na sala de aula, quer em casa. A diversidade de materiais disponíveis (canções, anúncios publicitários, poemas...) permite aos estudantes aceder a realizações linguísticas com diferentes graus de 
formalidade, possibilitando a análise de contextos situacionais diversificados e da sua adequação comunicativa (ALIMEMAJ, 2010). Através do iTunes é possível aceder a um grande número de páginas com ficheiros de áudio para a aprendizagem de línguas. A Open University britânica disponibiliza recursos para o estudo de línguas como o espanhol, o francês e o chinês (disponíveis em http://www.open.edu/itunes/subjects/languages), recorrendo a esta ferramenta, que se assume como um precioso auxiliar, numa aprendizagem autónoma.

Os computadores são também utilizados para a prática e o desenvolvimento da competência gramatical, através do alargamento vocabular e dos exercícios transformacionais (FITZPATRICK, 2004; HARRIS, et al., 2009; MILTON, 2002; VAN OLFEN et al. 2010; 2011; YOUNG et al., 2009; 2010). Contudo, a maior parte destes exercícios, bastante frequentes na aula de língua, continua a ser realizada em interfaces pouco atrativas e, por isso, a sua realização, sob a forma de jogos interativos, com cenários interessantes, assume-se como uma área que registará progressos significativos, nos próximos anos (MILTON, 2002).

O computador apresenta-se, também, como uma ferramenta útil para as atividades de compreensão oral, de leitura e de escrita e para a utilização de corpora linguísticos disponíveis em bases de dados acessíveis online (MILTON, 2002). Com a generalização do uso dos computadores, tornou-se recorrente a implementação de atividades de ensinoaprendizagem com o recurso a meios informáticos, geralmente conhecida pelo acrónimo CALL - Computer Assisted Language Learning, quer através de software específico, quer recorrendo a materiais e ferramentas existentes online.

Para além dos computadores, os dispositivos móveis também apresentam um elevado potencial educativo, no ensino de línguas. O m-learning (mobile learning), através do PDA, do telemóvel ou do Pocket PC, está, segundo Moura e Carvalho (2009, p. 22) «a abrir um novo capítulo na educação». O hibridismo destes media digitais, capazes de combinar texto, voz e imagem, favorece o recurso a várias dimensões do saber linguístico, permitindo o desenvolvimento da competência comunicativa dos estudantes de línguas e o desenvolvimento da aprendizagem colaborativa através, por exemplo, de um peddy-papper literário (MOURA \& CARVALHO, 2009).

Tendo em conta esta diversidade de ferramentas e de recursos, a utilização da tecnologia implica uma reflexão profunda, para que não se perca de vista o resultado esperado, no final de uma experiência de aprendizagem. Estudos realizados neste âmbito, e especificamente na aprendizagem de línguas, revelam que o desenvolvimento da competência 
comunicativa dos estudantes pode ser incrementado através do uso das novas tecnologias da comunicação. As situações de aprendizagem em que se utilizam recursos online constituem, para a generalidade dos estudantes, um fator de motivação, com impactos positivos nos resultados académicos (BUCHEM \& HAMELMANN, 2011; GENC ILTER, 2009; LENHART et al., 2008; RURATO E GOUVEIA, 2004; UNESCO, 2004; SHEN \& SUWANTHEP, 2011; SWAFFAR et al., 1998; ŻYGADŁO, 2007).

O enquadramento concetual apresentado nas primeiras páginas balizou a constituição de uma taxonomia de atividades com recurso à tecnologia, indo ao encontro das particularidades de cada disciplina (HARRIS et al., 2009; VAN OLFEN et al., 2010; 2011). Gizou-se, assim, um conjunto de 56 atividades possíveis para o desenvolvimento de cinco grandes dimensões do saber linguístico, na aprendizagem de línguas estrangeiras: a compreensão oral (listening), a expressão oral (speaking), a leitura (reading), a escrita (writing) e o visionamento (viewing).

A tabela I constitui uma amostra dessas atividades propostas por HARRIS et al. (2009) e VAN OLFEN et al. (2010; 2011), para cada uma das competências identificadas:

\begin{tabular}{|c|c|l|c|}
\hline Dimensão & $\begin{array}{c}\text { Tipo de } \\
\text { atividade }\end{array}$ & \multicolumn{1}{c|}{ Breve descrição } & $\begin{array}{c}\text { Tecnologias } \\
\text { possíveis }\end{array}$ \\
\hline $\begin{array}{c}\text { Compreensão } \\
\text { oral }\end{array}$ & $\begin{array}{c}\text { Ouvir uma } \\
\text { gravação audio }\end{array}$ & $\begin{array}{l}\text { Os estudantes ouvem uma } \\
\text { gravação, na língua } \\
\text { estrangeira, realizada pelos } \\
\text { colegas, pelo professor ou } \\
\text { produzida profissionalmente. }\end{array}$ & $\begin{array}{c}\text { Podcasts, site com } \\
\text { gravações áudio }\end{array}$ \\
\hline Expressão oral & $\begin{array}{c}\text { Conversação } \\
\text { colegam } \\
\text { grupo }\end{array}$ & $\begin{array}{l}\text { Os estudantes conversam com } \\
\text { um colega ou com um número } \\
\text { limitado de colegas, utilizando } \\
\text { a língua estrangeira (de forma } \\
\text { improvisada ou com um } \\
\text { propósito específico). }\end{array}$ & $\begin{array}{c}\text { Audio/vídeo } \\
\text { conferência, telefone }\end{array}$ \\
\hline Expressão \\
escrita & $\begin{array}{c}\text { Etiquetagem de } \\
\text { objetos }\end{array}$ & $\begin{array}{l}\text { Os estudantes preparam } \\
\text { etiquetas para colocar nos } \\
\text { objeto existentes na sala de } \\
\text { aula, em casa ou na escola }\end{array}$ & $\begin{array}{c}\text { Processador de texto, } \\
\text { programas } \\
\text { específicos para } \\
\text { desenho ou para a } \\
\text { construção de mapas } \\
\text { de conceitos. }\end{array}$ \\
\hline Leitura & $\begin{array}{c}\text { Ler uma banda } \\
\text { desenhada ou }\end{array}$ & $\begin{array}{l}\text { Os estudantes leem uma banda } \\
\text { desenhada/cartoon e }\end{array}$ & \begin{tabular}{c} 
Web \\
\hline
\end{tabular} \\
\hline
\end{tabular}




\begin{tabular}{|c|c|c|c|}
\hline & $\begin{array}{l}\text { um cartoon } \\
\text { político }\end{array}$ & $\begin{array}{l}\text { relacionam-na/o com as } \\
\text { realidades políticas } \\
\text { representadas. }\end{array}$ & \\
\hline Visionamento & $\begin{array}{c}\text { Ver uma } \\
\text { exposição }\end{array}$ & $\begin{array}{l}\text { Os estudantes realizam visitas } \\
\text { de estudo virtuais (museus de } \\
\text { arte, artefactos, trabalhos de } \\
\text { outros estudantes, exposições } \\
\text { da escola...) }\end{array}$ & $\begin{array}{l}\text { Web, } \\
\text { videoconferências, } \\
\text { visitas virtuais, } \\
\text { realizadas online. }\end{array}$ \\
\hline
\end{tabular}

Tabela I: Atividades-tipo para as aulas de língua segunda/estrangeira (tradução a partir do original de van Olphen et al. 2010; 2011).

Young et al. (2009; 2010) apresentam, igualmente, um conjunto de atividades-tipo, norteadas pelos princípios integradores do modelo TPACK, já explicitados, específico para as aulas de língua materna. Os autores agruparam as atividades tendo em conta cinco categorias, associadas a outras tantas competências do processo de aprendizagem da língua: leitura, escrita, funcionamento da língua/gramática, expressão oral e audição/visionamento. A tabela II mostra um exemplo de uma atividade passível de implementar, em aulas de língua materna, no domínio do conhecimento gramatical/funcionamento da língua.

\begin{tabular}{|c|c|l|c|}
\hline Dimensão & Tipo de atividade & \multicolumn{1}{|c|}{ Breve descrição } & Tecnologias possíveis \\
\hline $\begin{array}{c}\text { Funcionamento } \\
\text { da língua / }\end{array}$ & $\begin{array}{c}\text { Análise de } \\
\text { palavras } \\
\text { conhecimento } \\
\text { gramatical }\end{array}$ & $\begin{array}{l}\text { Os estudantes analisam as } \\
\text { palavras, sob diferentes } \\
\text { perspetivas, incluindo a as } \\
\text { suas origens (raízes, } \\
\text { afixos...), formação, funções } \\
\text { das palavras na frase }\end{array}$ & Dicionários online. \\
\hline
\end{tabular}

Tabela II: Atividades-tipo para as aulas de língua materna, no âmbito do funcionamento da língua/conhecimento gramatical (tradução a partir do original de Young et al. 2009; 2010).

O processo de aquisição/progressão em língua segunda, estrangeira ou materna privilegia, hoje, as abordagens comunicativas, consubstanciadas numa perspetiva socioconstrutivista do conhecimento, assente nos estudos de Bronckart e Vygotsky, entre outros. Para estes autores, a aquisição/progressão verbal resulta, por um lado, de uma interação entre o organismo e as suas capacidades próprias e, por outro, entre o meio físico e histórico-cultural (BRONCKART, 1985; VYGOTSKY, 1985). Há, nesta perspetiva, uma preocupação com a função comunicativa da linguagem, que se materializa numa constante relação interativa entre o sujeito, a língua e o contexto (PEMBERTON et al., 2005). A 
tecnologia pode, assim, assumir um papel importante, colocando o aluno numa posição de destaque, própria da abordagem comunicativa, favorecendo a interação entre os alunos e o professor (BUCHEM \& HAMELMANN, 2011; UNESCO, 2004).

É sobretudo ao nível da utilização da internet que o computador veio dar um importante contributo para a aprendizagem de línguas, possibilitando a interação entre falantes nativos, em situações autênticas de comunicação, algo que nem sempre se consegue concretizar nas aulas destinadas à aprendizagem de uma segunda língua (MILTON, 2002). Para além das múltiplas atividades possíveis de realizar em contextos de ensino tradicionais, as redes de aprendizagem online e a expansão do ensino a distância, utilizando o computador, possibilitaram novas formas de aprender línguas, recorrendo a novos media.

\section{APRENDER LÍNGUAS A DISTÂNCIA}

Quando, em 1856, em Berlim, Charles Toussaint e Gustav Langenscheidt fundaram a primeira escola por correspondência destinada à aprendizagem de línguas (PIMENTEL, 2006; RURATO \& GOUVEIA, 2004) estavam longe de imaginar o impacto que a sua criação teria nas gerações futuras. Até aos dias de hoje, a aprendizagem de línguas a distância tem sido uma modalidade amplamente utilizada, quer na sua forma mais tradicional, recorrendo, apenas, ao material impresso, quer conjugando materiais em suportes diversificados. A geração inaugural da educação a distância $(\mathrm{EaD})$, baseou-se na utilização dos serviços postais e recorria ao material impresso (GOMES, 2003; MAJUMDAR, 2003; PIMENTEL, 2006; RURATO \& GOUVEIA, 2004; SUMNER, 2000).

Na segunda geração de ensino a distância, surgem já incorporados vários meios, como a televisão, as gravações áudio e, em alguns casos, os primeiros materiais didáticos gravados em disquetes (MAJUMDAR, 2003; SUMNER, 2000). No caso das línguas, esta geração de ensino a distância caracterizou-se pela utilização de métodos audiolinguais, em que os estudantes ouviam os registos áudio, tentavam responder a questionários e repetiam o que era ouvido. Desta forma, aperfeiçoavam a pronúncia, prestando-se, assim, uma maior atenção ao domínio da oralidade, ausente da primeira geração de cursos de línguas por correspondência. Esta geração de $\mathrm{EaD}$ conjuga materiais próprios da primeira (o material impresso) com os meios audiovisuais. Em Portugal, a criação da Telescola (1964), a iniciativa Ano Propedêutico (1977) e a fundação da Universidade Aberta (1988) ilustram o modus operandi, nesta segunda geração de $\mathrm{EaD}$, assente, fundamentalmente, «na produção e na distribuição de 
materiais pedagógicos» (MAJUMDAR, 2003, p. 22). Esta geração de ensino a distância pode ser ilustrada, ainda, pela transmissão, na Radio Televisão Portuguesa, a estação pública de televisão, de cursos de línguas, como o Follow Me!, produzido pela BBC, nos finais da década de 70, e destinado a ensinar inglês a pessoas adultas ${ }^{2}$.

Nestas duas gerações, os baixos níveis de interação existentes, muitas vezes, apenas, entre o estudante e o conteúdo (MAJUMDAR, 2003; MORGADO, 2003; SUMNER, 2000) constituíam um óbice ao desenvolvimento da competência comunicativa, num contexto de aprendizagem de uma língua. Hoje, o recurso à internet permite níveis de interação que noutras modalidades de ensino a distância, anteriores, dificilmente seriam alcançáveis.

A Comissão Europeia tem apoiado projetos em rede, destinados ao estudo de uma segunda língua (MILTON, 2002) e, por todo o mundo, são múltiplas as iniciativas destinadas à aprendizagem de línguas, de modo não-formal e formal, recorrendo aos novos media (UNESCO, 2004; WHITE, 2003). Presentemente, estão disponíveis online várias plataformas e redes sociais destinadas à aprendizagem de línguas, em contextos não-formais, como é o caso da Palabea. Os membros desta plataforma podem encontrar falantes nativos e interagir, de forma síncrona, através de vídeo-chat, e assíncrona, utilizando o correio eletrónico, fora de discussão, documentos escritos e podcasts. A interface, bastante organizada, permite diferentes formas de comunicação, privilegiando a interação dos utilizadores, que podem escolher as línguas que lhes interessam e indicar qual é a sua língua materna. Desta forma, o mesmo utilizador pode desempenhar os papéis de aluno ou de professor, de acordo com o seu nível de proficiência linguística.

As potencialidades criadas pelo ensino online promoveram a sociedade em rede (MORGADO, 2003) e vice-versa, trazendo novas possibilidades de interação que estão longe de se encontrar esgotadas, como ilustram plataformas como a Palabea e tantas outras disponíveis online $e^{3}$.

As novas tecnologias trouxeram outras formas de desenvolver e de implementar abordagens comunicativas, no ensino e na aprendizagem de línguas, conferindo à oralidade e

\footnotetext{
2 Esses programas podem, hoje, ser vistos online, recorrendo ao YouTube (veja-se, por exemplo, em http://www.youtube.com/watch?v=PGiNjI1j2P4).

${ }^{3}$ Uma rápida pesquisa na internet permite-nos encontrar dezenas de plataformas e de redes sociais dedicadas à aprendizagem das línguas, semelhantes à Palabea. Diposnibilizam-se, aqui, os endereços web de algumas delas, que deverão ser entendidads como meros exemplos de uma realidade cada vez mais ampla, possibilitada pelas facilidades tecnológicas da sociedade da informação em rede: http://www.livemocha.com/; http://www.italki.com/;http:/www.babbel.com/go/friendsabroad;http://www.sharedtalk.com/;http://www.mylan guageexchange.com/; http://www.myngle.com/; http://www.polyglot-learn-language.com/; http://lang-8.com/; http://www.mangolanguages.com/.
} 
à interação entre os estudantes um lugar de destaque, inexistente, durante muitos anos, na EaD. A comunicação estabelecida em comunidades de aprendizagem em rede permite aos seus utilizadores comunicar de uma forma mais confiante e com maior entusiasmo (SWAFFAR et al., 1998).

Nos cursos de línguas online oferecidos pela Open University do Reino Unido, é disponibilizada uma plataforma multimodal, em rede, denominada Lyceum, criada em 1997. Esta oferece a possibilidade de trabalhar de forma síncrona, através de audioconferência e de chat, e assíncrona, recorrendo ao forum de discussão (HAMPEL E HAUCK, 2006; LAMY, 2006). Procura-se, assim, recriar um ambiente semelhante ao de uma sala de aula presencial, permitindo a apresentação de imagens, a redação coletiva de textos e a possibilidade de desenvolver a interação oral a distância (LAMY, 2006).

Se, por um lado, a ausência de comunicação face a face pode constituir um obstáculo ao desenvolvimento das competências de expressão oral (TRAJANOVIC et al., 2007), por outro, o desenvolvimento tecnológico tem permitido a inclusão de ferramentas de comunicação síncrona, como a áudio e a videoconferência (HAMPEL \& HAUCK, 2006) que permitem a implementação de uma verdadeira pedagogia da oralidade, na rede e em rede, seja em contextos formais, seja não-formais.

\section{Conclusão e perspetivas}

Ao longo dos séculos, o ensino-aprendizagem de línguas lançou sempre a mão às tecnologias existentes. A crescente reflexão sobre as relações entre o conhecimento tecnológico e o conhecimento pedagógico desenvolve no professor uma maior expertise, quer no manuseamento da tecnologia, quer na sua adequação aos conteúdos e aos resultados de aprendizagem que se pretendem alcançar.

Os novos cenários de utilização da tecnologia trouxeram novas possibilidades de comunicação entre os estudantes, recorrendo a diferentes línguas. Em todo o mundo, há, agora, a possibilidade de comunicar livre e instantaneamente, com outras pessoas, por mais distantes que possam estar. O e-learning, o m-learning, a aprendizagem de línguas em ambientes imersivos, como o Second Life ${ }^{\circledR}$ (SILVA, 2010) e a televisão interativa (PEMBERTON et al., 2005; FALLAHKHAIR, 2004) permitem novas formas de desenvolver a competência comunicativa, sobretudo no âmbito da oralidade, facilitando o contacto com falantes nativos, de forma síncrona. É, sobretudo, ao nível do desenvolvimento das 
competências de oralidade que a utilização da tecnologia, na educação em línguas, constitui um desafio interessante e ainda pouco estudado.

Os novos cenários tecnológicos, através de ensino a distância, apresentam um elevado potencial na preservação das línguas minoritárias (MILTON, 2002; UNESCO, 2004), menos procuradas ou menos estudadas. A crescente procura do conhecimento, por parte de novos públicos, ao longo da vida, por múltiplas razões, pode constituir uma oportunidade para o desenvolvimento de iniciativas destinadas a aprender línguas online, que exigem novos desenhos curriculares e abordagens adequadas ao perfil desses públicos.

A associação de diferentes media, difusores de texto, de som e de imagem, num ambiente de aprendizagem online, pode ser benéfica para o estudante de línguas (CAN, 2009). Uma aprendizagem de línguas baseada numa perspetiva construtivista implica, também, a autonomia do estudante no desenvolvimento de uma competência comunicativa holística, contemplando as diferentes dimensões do saber linguístico e intercultural. Porque as línguas que aprendemos na escola poderão não ser aquelas de que necessitamos para os vários propósitos da nossa vida, a aprendizagem de línguas é uma das áreas de expansão da formação ao longo da vida que implicará a tomada de decisões corajosas por parte das instituições responsáveis pela formação, pelo ensino e, até, pelas políticas linguísticas.

\section{Referências}

ALIMEMAJ, Zamira. YouTube, language learning and teaching techniques. AngloHigher The Magazine of Global English Speaking Higher Education. Volume 2, Issue 3, 2010. Disponível em http://www.anglohigher.com/magazines/magazine_detail/61/32. Acesso em 14 abr. 2012.

ANDRADE, Ana Isabel; ARAÚJO e SÁ, Maria Helena A. B. de. Didáctica da língua estrangeira. Rio Tinto: Asa, 1992.

ARAÚJO, Luísa. Portugal numa Europa que se quer multilingue. In MUÑOZ, Carmen et al. Aprender uma segunda língua. Lisboa: Fundação Francisco Manuel dos Santos/Porto Editora, 2011 (pp. 39-57).

BERTRAND, Y. Remarques sur les objectifs de l' enseignement des langues. Les langues modernes. N. ${ }^{\circ}$ 3, 1997 (pp. 215-230).

BUCHEM, Ilona; HAMELMANN. Developing 21st century skills: web 2.0 in higher education - a case study. Elearning papers. N. ${ }^{\circ} 24,2011$. Disponível em http://www.elearningeuropa.info/en/article/Developing-21st-century-skills\%3A-Web-2.0-inhigher-education.-A-Case-Study. Acesso em 29 abr. 2012. 
BRONCKART, J.-P. Les sciences du langage: un défi pour l' enseignement? Lausanne: UNESCO-Delachaux \& Niestlé, 1985.

CAN, Tuncer. Learning and teaching languages online: a constructivist approach. NovitasRoyal. Volume 3 (1), 2009 (pp. 60-74). Disponível em http://novitasroyal.org/Vol_3_1/can.pdf. Acesso em 17 mar. 2012.

COMISSÃO DAS COMUNIDADES EUROPEIAS. Multilinguismo: uma mais-valia para a Europa e um compromisso comum. COM (2008) 566, 2008. Disponível em http://ec.europa.eu/languages/documents/2008_0566_pt.pdf. Acesso em 8 mar. 2012.

COMISSÃO DAS COMUNIDADES EUROPEIAS. Communication from the Commission to the Council, the European Parliament, the European Economic and Social Committee and the Committee of the Regions: Promoting language learning and linguistic diversity: an action plan 2004-2006. COM (2003) 449, 2003. Disponível em http://ec.europa.eu/education/doc/official/keydoc/actlang/act_lang_en.pdf. Acesso em 8 mar. 2012.

CONDE, Xavier Frías. Qué gran inventu 'I blogue, 2012. Disponível em http://lhenguasnunstatalesilastics.blogspot.com. Acesso em 8 mar. 2012.

CONOLE, G.; ALEVIZOU, P. A literature review of the use of web 2.0 tools in higher education. Walton Hall, Milton Keynes, UK: The Open University, 2010. Disponível em http://www.heacademy.ac.uk/assets/EvidenceNet/Conole_Alevizou_2010.pdf. Acesso em 15 abr. 2012.

COUTINHO, Clara Pereira; BOTTENTUIT JUNIOR, João Batista. Comunicação educacional: do modelo unidireccional para a comunicação multidireccional na sociedade do conhecimento. Comunidade e cidadania: actas do $5 .^{\circ}$ Congresso da Sociedade Portuguesa de Ciências da Comunicação. Braga: Universidade do Minho, 2007. Disponível em http://hdl.handle.net/1822/7770. Acesso em 12 abr. 2012.

FALLAHKHAIR, S.; MASTHOFF, J.; PEMBERTON, L. Learning languages from interactive television: language learners reflect on techniques and technologies. CANTONI, L.; MCLOUGHLIN, C. (Eds.). World Conference on Educational Multimedia, Hypermedia \& Telecommunications EdMedia 2004. Norfolk, USA: AACE, 2004(p. 4336-4343). Disponível em http://www.abdn.ac.uk/ csc263/Publications/EdMedia04.pdf. Acesso em 24 abr. 2012.

FITZPATRICK, Anthony. Information and communication technology in foreign language teaching and learning - an overview. Analytical survey - Information and communication technologies in the teaching and learning of foreign languages: state-of-the-art, needs and perspectives. Moscow: UNESCO Institute for Information Technologies in Education, 2004 (op. 10-26). Disponível em http://iite.unesco.org/pics/publications/en/files/3214627.pdf. Acesso em 16 abr. 2012.

FRANKLIN, T.; van HARMELEN, M. Web 2.0 for content for learning and teaching in higher education, 2007. Disponível em http://ie-repository.jisc.ac.uk/148/1/web2-content- 
learning-and-teaching.pdf. Acesso em 13 abr. 2012.

GENC ILTER, Binnur. Effect of technology on motivation in EFL classrooms. Turkish online journal of distance education-TOJDE. Volume 10 N. ${ }^{\circ}$ 4. Article 9, 2009. Disponível em https://tojde.anadolu.edu.tr/tojde36/pdf/Volume10Number4.pdf. Acesso em 17 abr. 2012.

GOMES, Maria João. Gerações de inovação tecnológica no ensino a distância. Revista portuguesa de educação, 16 (1). Braga: Centro de Investigação em Educação -Universidade do Minho, 2003 (pp.137-156). Disponível em https://repositorium.sdum.uminho.pt/handle/1822/496. Acesso em 15 abr. 2012.

HAMPEL, Regine; HAUCK, Mirjam. Computer-mediated language learning: Making meaning in multimodal virtual learning spaces. The JALT CALL Journal. Volume. 2. N. ${ }^{\circ} 2$, 2006 (pp. 3-18). Disponível em http://www.jaltcall.org/journal/articles/2_2_Hampel.pdf. Acesso em 17 abr. 2012.

HARRIS, J.; HOFER, M. Instructional planning activity types as vehicles for curriculumbased TPACK development. MADDUX, C. D., (Ed.). Research highlights in technology and teacher education. Chesapeake, VA: Society for Information Technology in Teacher Education (SITE), 2009 (pp. 99-108). Disponível em http://activitytypes.wmwikis.net/file/view/HarrisHofer-TPACKActivityTypes.pdf. Acesso em 14 abr. 2012.

HARRIS, Judith; MISHRA, Punya; KOEHLER, Matthew. Teacher's technological pedagogical content knowledge and learning activity types: curriculum-based technology integration reframed. Journal of Research on Technology in Education. Volume 41. N. ${ }^{\circ}$, 2009 (pp. 393-416)

LENHART, Amanda; ARAFEH, Sousan; SMITH, Aaron; MACGILL, Alexandra Rankin Writing, technology and teens. Pew internet \& american life project, 2008. Disponível em http://www.pewinternet.org/ /media//Files/Reports/2008/PIP_Writing_Report_FINAL3.pdf.p df. Acesso em 2 abr. 2012.

MAJUMDAR, Shyamal. Definir um sistema pedagógico para a formação online. Revista europeia formação profissional. N. ${ }^{\circ}$ 28, 2003 (pp. 21-32). Disponível em http://www.cedefop.europa.eu/etv/Upload/Information_resources/Bookshop/341/28_pt_maju mdar.pdf. Acesso em 7 abr. 2012.

MCLUHAN, Marshall. Compreender os meios de comunicação - extensões do homem. Lisboa: Relógio d’Água, 2008.

MILTON, James. Literature review in languages, technology and learning. Futurelab, 2002. Disponível em www.futurelab.org.uk/researc/lit_reviews.htm. Acesso em 7 abr. 2012. MISHRA, P.; KOEHLER, M. J. Technological pedagogical content knowledge: a framework for integrating technology in teachers' knowledge. Teachers College Record. 108 (6), 2006 (pp. 1017-1054).

MORGADO, Lina. Os novos desafios do tutor a distância: o regresso ao paradigma da sala de aula. Discursos - Novos rumos e pedagogia em ensino a distância. Lisboa: Universidade Aberta, 2003 (pp. 77-89). 
MOURA, Adelina; CARVALHO, Ana Amélia. Peddy-paper literário mediado por telemóvel. Educação, Formação e Tecnologias [Em linha]. 2:2. p. 22-40, 2009. Disponível em http://hdl.handle.net/1822/9893. Acesso em 18 abr. 2012.

PAIVA, Vera Lúcia Menezes de Oliveira e. O uso da tecnologia no ensino de línguas estrangeiras: breve retrospectiva histórica, s.d. Disponível em http://www.veramenezes.com/techist.pdf. Acesso em 19 abr. 2012.

PEMBERTON, L.; FALLAHKHAIR, S.; MASTHOFF, J. Learner centred development of a mobile and iTV language learning support system. Educational Technology \& Society. 8 (4), 2005 (pp. 52-63). Disponível em http://www.ifets.info/journals/8_4/7.pdf. Acesso em 14 abr. 2012.

PIMENTEL, Nara Maria. Educação a distância. Florianópolis: SEAD/UFSC, 2006. Disponível em http://www.faad.icsa.ufpa.br/admead/documentos/submetidos/conteudo_ead.pdf.pdf. Acesso em 19 abr. 2012.

POP, Anisoara. The impact of the new technologies in foreign language instruction our experience. Procedia - Social and Behavioral Sciences, Volume 2, Issue 2, 2010 (pp. 11851189). Disponível em http://www.sciencedirect.com/science/article/pii/S1877042810002090. Acesso em 20 abr. 2012.

RUBIN, Joan; THOMPSON, Irene. How to be a more successful language learner. Boston: Heinle and Heinle Publishers, 1994.

RURATO, Paulo; GOUVEIA, Luís Borges. História do ensino a distância: uma abordagem estruturada. Revista da Faculdade de Ciências Humanas e Sociais. Porto: Universidade Fernando Pessoa, p. 159-168, 2004. Disponível em http://hdl.handle.net/10284/635. Acesso em 25 abr. 2012.

SHEN, Lin; SUWANTHEP, Jitpanat. E-learning constructive role plays for EFL learners in China’s tertiary education. Asian AFL Journal. Volume 49, 2011. Disponível em http://www.asian-efl-journal.com/PTA/January_2011_Shen.pdf. Acesso em 19 abr. 2012.

SILVA, Sara. O Second Life ${ }^{\circledR}$ e o ensino-aprendizagem de Inglês. Dissertação de mestrado apresentada à Universidade de Aveiro. Aveiro: Universidade de Aveiro, 2010.

SUMNER, Jennifer. Serving the system: a critical history of distance education. Open Learning. Volume. 15, N. . 3, 2000. Disponível em http://pages.towson.edu/bsadera/istc717/modules05/module8/3888263.pdf. Acesso em 16 abr. 2012.

SWAFFAR, Janet; ROMANO, Susan; MARKLEY e ARENS Katherine (Ed.). Language Learning Online: Theory and Practice in the ESL and L2 Computer Classroom. Austin: The Daedalus Group. 1998. Disponível em http://www.daedalus.com/downloads_public/llo/llo_standard.pdf. Acesso em 19 abr. 2012. TRAJANOVIC, Miroslav; DOMAZET, Dragan; MISIC-ILIC, Biljana. Distance learning and foreign language teaching, 2007. Disponível em http://hal.archives- 
ouvertes.fr/docs/00/19/00/64/PDF/441-452.pdf. Acesso em 20 abr. 2012.

UNESCO. Analytical survey - information and communication technologies in the teaching and learning of foreign languages: state- of-the-art, needs and perspectives. Moscow:

UNESCO Institute for Information Technologies in Education, 2004. Disponível em http://iite.unesco.org/pics/publications/en/files/3214627.pdf. Acesso em 14 abr. 2012.

van OLPHEN, M.; HOFER, M.; \& HARRIS, J. World languages learning activity types. College of William and Mary, School of Education, Learning Activity Types Wiki, 2011. Disponível em http://activitytypes.wmwikis.net/file/view/WorldLanguagesLearningATsFeb2011.pdf. Acesso em 18 abr. 2012.

van OLPHEN, M.; HOFER, M.; \& HARRIS, J. Grounded tech integration: world languages. Learning and leading with technology. Volume 37. N. ${ }^{\circ}$ 4, 2010 (pp. 26-28). Disponível em http://www.learningandleading-digital.com/learning_leading/200912\#pg1. Acesso em 20 abr. 2012.

VYGOTSKY, L. S. Pensée et langage. Paris: Editions Sociales, 1985.

WHEELER, S. Learning space mashups: combining web 2.0 tools to create collaborative and reflective learning spaces. Future internet, 1, , 2009 (pp. 3-13). Disponível em http:// www.mdpi.com/1999-5903/1/1/3/pdf. Acesso em 18 abr. 2012.

WHITE, Cynthia. Language Learning in Distance Education. Cambridge: Cambridge University Press, 2003.

YOUNG, C. A.; HOFER, M.; \& HARRIS, J. Secondary english language arts learning activity types. College of William and Mary, School of Education, Learning Activity Types Wiki, 2009. Disponível em http://activitytypes.wmwikis.net/file/view/SecEngLangArtsLearningATs-Feb09.pdf. Acesso em 21 abr. 2012.

YOUNG, C. A.; HOFER, M.; HARRIS, J. Grounded tech integration: english language arts. Learning and leading with technology. Volume 37. N. ${ }^{\circ}$ 5, 2010 (pp. 28-30). Disponível em http://www.learningandleading-digital.com/learning_leading/201002\#pg1. Acesso em 21 abr. 2012.

ŻYGADŁO, Przemysław. Computer-Assisted Language Learning: effectiveness of vocabulary learning with the help of the authorial on-line application of the Catch'n'Practise v 1.0., Uniwersytet Warszawski, 2007. Disponível em http://www.jezykowcy.pl/documents/praca_licencjacka.pdf. Acesso em 24 abr. 2012.

Recebido em: julho de 2012 Aprovado em: novembro de 2012 